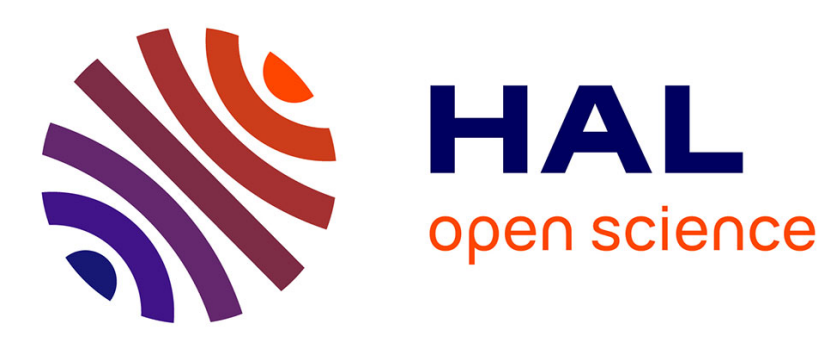

\title{
High temperature low cycle fatigue behaviour of a martensitic forging tool steel
}

Gérard Bernhart, G Moulinier, Olivier Brucelle, Denis Delagnes

\section{To cite this version:}

Gérard Bernhart, G Moulinier, Olivier Brucelle, Denis Delagnes. High temperature low cycle fatigue behaviour of a martensitic forging tool steel. International Journal of Fatigue, 1999, 21 (2), pp.179-186. 10.1016/S0142-1123(98)00064-4 . hal-01701678

\section{HAL Id: hal-01701678 \\ https://hal.science/hal-01701678}

Submitted on 11 Jan 2019

HAL is a multi-disciplinary open access archive for the deposit and dissemination of scientific research documents, whether they are published or not. The documents may come from teaching and research institutions in France or abroad, or from public or private research centers.
L'archive ouverte pluridisciplinaire HAL, est destinée au dépôt et à la diffusion de documents scientifiques de niveau recherche, publiés ou non, émanant des établissements d'enseignement et de recherche français ou étrangers, des laboratoires publics ou privés. 


\title{
High temperature low cycle fatigue behaviour of a martensitic forging tool steel
}

\author{
G. Bernhart *, G. Moulinier, O. Brucelle, D. Delagnes \\ Material Research Center, Ecole des Mines d'Albi-Carmaux, 81000 Albi, France
}

\begin{abstract}
High temperature low cycle fatigue tests have been carried out on a $55 \mathrm{NiCrMoV} 8$ martensitic steel in the temperature range $200^{\circ} \mathrm{C}$ to $550^{\circ} \mathrm{C}$. At all temperatures, the material shows evidence of cyclic softening. Manson-Coffin and Basquin analysis is applied for lifetime analysis. An elasto-plastic kinematic and isotropic hardening model, taking into account the strain path history, was identified using the isothermal LCF tests. Identification methodology is presented and the model validated by comparing experimental and predicted evolution of hysteresis loops during symmetrical and non-symmetrical total strain LCF testing.
\end{abstract}

Keywords: Low cycle fatigue; Martensitic tool steel; Cyclic stress-strain modelling

\section{Introduction}

During hot-forging operations, the tool is subjected to both mechanical and thermal loads. During the die filling process, mechanical stress analysis on cold-forging tools have shown, [1,2], that the highly stressed transition radii of the tools are subjected to cyclic plastic deformation which causes crack initiation.

When working with high temperature workpieces, the surface of the tool undergoes further thermal cycling $[3,4]$, which is the result of the successive hot forging, waiting periods and lubricating operations. Die material is subject to high temperature Low Cycle Fatigue (LCF) and Thermomechanical Fatigue (TMF).

The lifetime of the tools can only be increased by a better knowledge of the fatigue behaviour of the tool steel, and the use of adequate behaviour laws during the designing stage.

In the present study the high temperature Low Cycle Fatigue behaviour of a 55NiCrMoV8 tool steel has been investigated. This steel is classified within the mechanical impact resistant steels, and is commonly used in the forging industry on mechanical and hydraulic presses.
The level of strain amplitude has been selected so as to reach the rupture of the specimens between a few hundred and a few thousand cycles, which corresponds to the industrial lifetime between repairs. The non-saturating cyclic softening behaviour is analysed and MansonCoffin and Basquin lifetime analysis is applied.

The isothermal cyclic stress-strain behaviour is described with an elasto-plastic non-linear kinematic and isotropic hardening model formulated in the framework of the thermodynamics of irreversible processes. The development of these models was largely driven by the needs of the aeronautical industry (nickel based superalloys $[5,6]$ ) and nuclear industry (stainless steels $[7,8]$ ). But only little attempt was made to apply such models to other kinds of materials. Nevertheless the elasto-plastic behaviour of bainitic steels [9] and the viscoplastic behaviour of $12 \%$ chromium martensitic steel coatings [10] have been successfully modelled. The methodology of the variable (kinematic and isotropic) selection and model coefficient identification is explained. The predictive capability of the model has been verified in conducting non-symmetrical Low Cycle Fatigue tests.

* Corresponding author. Tel.: + 33-5-63-49-30-56; Fax: + 33-563-49-30-99; E-mail: bernhart@enstimac.fr 
Table 1

Chemical composition (wt $\%$ )

\begin{tabular}{lllllllll}
\hline $\mathrm{C}$ & $\mathrm{Ni}$ & $\mathrm{Cr}$ & $\mathrm{Mo}$ & $\mathrm{V}$ & $\mathrm{Si}$ & $\mathrm{Mn}$ & $\mathrm{P}$ & $\mathrm{S}$ \\
0.56 & 1.70 & 1.10 & 0.50 & 0.10 & 0.20 & 0.7 & $\leq 0.025$ & $\leq 0.025$ \\
\hline
\end{tabular}

\section{Experimental procedures}

\subsection{Tool steel material}

The material investigated in this study is a martensitic tool steel used in hot forging. The chemical composition of the 55NiCrMoV8 (EN 10027-1) is given in Table 1.

Test specimens were machined in an as-recieved 55 $\mathrm{mm}$ diameter forged rod. Before final grinding, the following heat treatment was performed: austenizing heating to $875^{\circ} \mathrm{C}$ for $1 \mathrm{~h}$, oil quenching, tempering for $2 \mathrm{~h}$ at $510^{\circ} \mathrm{C}$ and air cooling. The achieved hardness is 47 HRC (Rockwell hardness).

Microstructural investigations have shown that this steel contains numerous sulfide inclusions. Moreover, angular shaped inclusion alignments of $150 \mu \mathrm{m}$ long are observed. Austenitic grain size measured in etched specimens is $20 \mu \mathrm{m}$. The fine lath martensitic structure contains numerous fine carbides (Fig. 1).

\subsection{Test procedure and test plan}

Fatigue test specimens with a gauge diameter of $9 \mathrm{~mm}$ and a gauge length of $14 \mathrm{~mm}$ are polished with emery paper $\left(R_{\mathrm{a}}<0.02 \mu \mathrm{m}\right)$.

LCF tests are performed under total strain control with a closed-loop Schenck Hydropuls $250 \mathrm{kN}$ servohydraulic testing machine. Heating of specimens is achieved with a $1000^{\circ} \mathrm{C}$ resistive furnace. Superalloy tools were used to grip the test specimens. Maximum temperature gradient over the extensometer gauge length was recorded to be lower than $4^{\circ} \mathrm{C}$ up to a test temperature of $550^{\circ} \mathrm{C}$.

Strain is recorded with a $10 \mathrm{~mm}$ gauge length contact

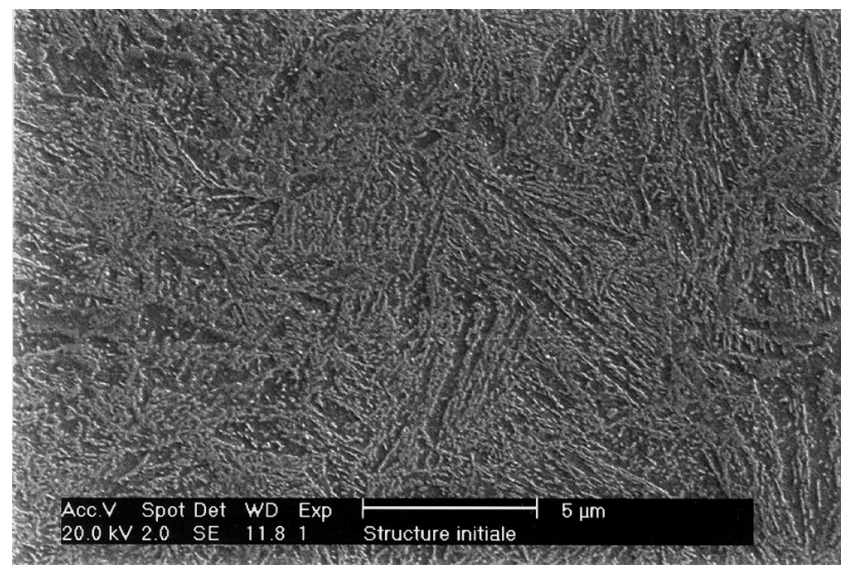

Fig. 1. Martensitic structure and carbides. extensometer with alumina rods. Total strain amplitude fatigue tests, with a zero mean strain, are conducted at a frequency of 0.4 hertz under triangular wave form up to rupture of the specimens. This frequency was chosen as a typical frequency for mechanical hot forging presses.

The temperature test range is $200^{\circ} \mathrm{C}$ to $550^{\circ} \mathrm{C}$ whereas the total strain amplitude ranges from $1 \%$ to $2 \%$. With respect to the frequency, strain rate varies from 0.008 to $0.0144 \mathrm{~s}^{-1}$. Specimens are assumed to be fractured if a $10 \%$ rapid drop of load is observed.

Fatigue stress-strain loops are acquired by a computer for a predefined number of cycles. Maximum and minimum stress are recorded for each cycle.

\section{Fatigue test results}

\subsection{General results}

Number of cycles to rupture $N_{\mathrm{f}}$, semi-stress amplitude $\Delta \sigma_{\mathrm{m}} / 2$ and plastic strain amplitude $\Delta \epsilon_{\mathrm{pm}}$ at "half-life" are summarized in Table 2 for all the tests. Some tests show evidence of premature fatigue crack initiation at extensometer rod tip; they are identified in the table. At $400^{\circ} \mathrm{C}$ several ruptures were initiated by macro-cracks growing outside the extensometer gauge length, and only one third of the cyclic stress-strain curves can be used for further analysis.

At low temperatures $\left(200^{\circ} \mathrm{C}\right.$ to $\left.400^{\circ} \mathrm{C}\right)$, careful observations of the fracture surface and the lateral surface clearly show that initiation mainly takes place at nonmetallic-inclusions (essentially manganese sulfide) located near the surface. At $500^{\circ} \mathrm{C}$ and $550^{\circ} \mathrm{C}$, initiation of cracks is localized in strongly oxidized zones. The crack propagation is always transgranular independently of strain amplitudes and testing temperatures.

\subsection{Cyclic strain softening}

For all temperature and strain amplitudes investigated in this study, the material exhibits a cyclic strain softening behaviour, without stabilization of the stress.

Softening depends on the temperature and the initial total strain amplitude. Fig. 2 shows the evolution of the semi-stress amplitude $\Delta \sigma / 2$ with respect to the number of cycles for several total strain amplitudes and temperatures. The material shows evidence of very high cyclic softening; varying between $30 \mathrm{MPa}$ and $200 \mathrm{MPa}$ 
Table 2

General results of LCF tests

\begin{tabular}{|c|c|c|c|c|}
\hline Temperature $\left({ }^{\circ} \mathrm{C}\right)$ & $\begin{array}{l}\text { Total strain amplitude } \\
\Delta \epsilon_{\mathrm{t}}(\%)\end{array}$ & $\begin{array}{l}\text { Number of cycles to } \\
\text { rupture }\left(N_{\mathrm{f}}\right)\end{array}$ & $\begin{array}{l}\text { Semi-stress amplitude at } \\
\text { "half-life" } \Delta \sigma_{\mathrm{m}} / 2(\mathrm{MPa})\end{array}$ & $\begin{array}{l}\text { Plastic strain amplitude at } \\
\text { "half-life" } \Delta \epsilon_{\mathrm{pm}}(\%)\end{array}$ \\
\hline \multirow[t]{3}{*}{200} & 1.2 & 7690 & 900 & 0.18 \\
\hline & 1.4 & 4010 & 969 & 0.31 \\
\hline & 1.6 & 2579 & 1007 & 0.47 \\
\hline \multirow[t]{5}{*}{300} & 1.1 & 9296 & 945 & 0.11 \\
\hline & 1.2 & 6210 & 958 & 0.14 \\
\hline & 1.4 & 4356 & $1023\left(^{\mathrm{a}}\right)$ & 0.26 \\
\hline & 1.6 & 2700 & 1057 & 0.37 \\
\hline & 1.8 & 1795 & 1101 & 0.51 \\
\hline \multirow[t]{5}{*}{400} & 1.2 & 6294 & $869\left(^{b}\right)$ & 0.11 \\
\hline & 1.3 & 4280 & $946\left(^{b}\right)$ & 0.20 \\
\hline & 1.4 & 2709 & $961\left(^{b}\right)$ & 0.28 \\
\hline & 1.5 & 3113 & 962 & 0.32 \\
\hline & 1.6 & 2240 & $952\left(^{a}\right)$ & 0.43 \\
\hline \multirow[t]{6}{*}{500} & 1.0 & 12780 & 709 & 0.07 \\
\hline & 1.2 & 4313 & 823 & 0.18 \\
\hline & 1.3 & 1941 & $795\left(^{a}\right)$ & 0.29 \\
\hline & 1.4 & 1907 & $816\left({ }^{a}\right)$ & 0.31 \\
\hline & 1.6 & 1410 & 829 & 0.55 \\
\hline & 2.0 & 840 & 901 & 0.77 \\
\hline \multirow[t]{4}{*}{550} & 0.9 & 7755 & $596\left({ }^{a}\right)$ & 0.09 \\
\hline & 1.0 & 5066 & 655 & 0.15 \\
\hline & 1.2 & 2303 & 707 & 0.30 \\
\hline & 1.4 & 1221 & 716 & 0.47 \\
\hline
\end{tabular}

(a) Initiation of a crack outside the extensometer gauge length.

(b) Initiation of macrocrack outside the gauge length.

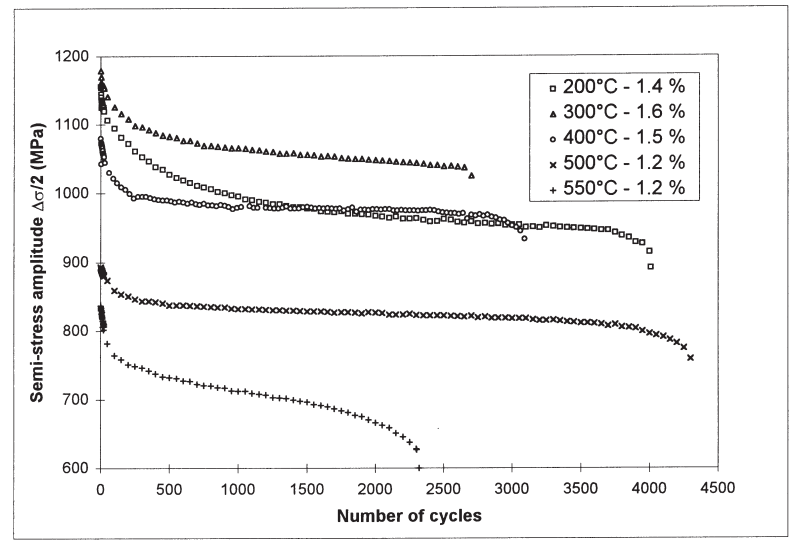

Fig. 2. Cyclic softening behaviour.

depending on temperature and strain amplitude, this softening can reach up to $30 \%$ of the first cycle amplitude.

Such a behaviour, also noticed in martensitic 5\% chromium tool steels [11], is commonly explained as follows: the initial high dislocation density which results from the quenching, decreases during cycling and generates dislocation cell structures [12].

\subsection{Fatigue life}

Fatigue life results were plotted-using the conventional definition of "half-life" [13] - for each temperature (Fig. 3) in terms of the Manson-Coffin relationship by $\Delta \epsilon_{\mathrm{pm}} / 2=\epsilon_{\mathrm{f}}^{\prime} \cdot\left(2 N_{\mathrm{f}}\right)^{c}$ where $\Delta \epsilon_{\mathrm{pm}}$ is the total plastic strain amplitude at 'half-life', $2 N_{\mathrm{f}}$ the number of reversals to failure, $\epsilon_{\mathrm{f}}^{\prime}$ the fatigue ductility and $c$ the fatigue ductility exponents.

Combined with the Basquin relationship, $\Delta \epsilon_{\mathrm{em}} / 2=$

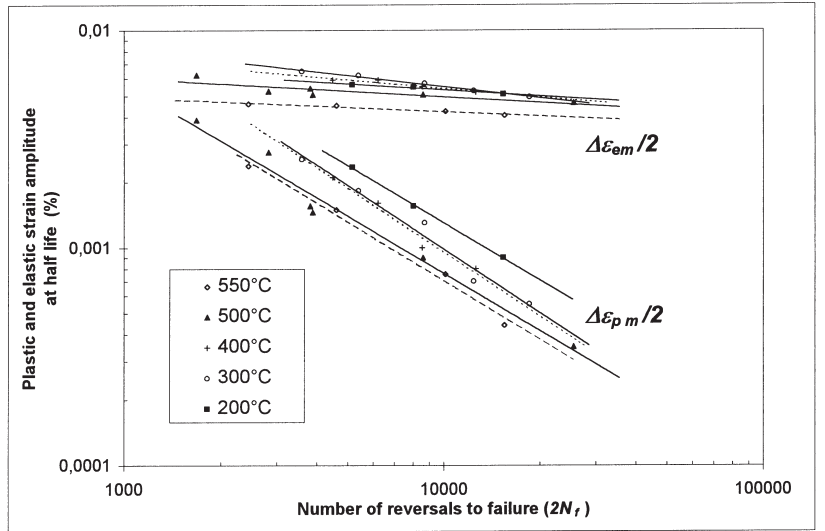

Fig. 3. Manson-Coffin and Basquin plots. 
Table 3

Fatigue life coefficients

\begin{tabular}{|c|c|c|c|c|c|}
\hline Temperature & $200^{\circ} \mathrm{C}$ & $300^{\circ} \mathrm{C}$ & $400^{\circ} \mathrm{C}$ & $500^{\circ} \mathrm{C}$ & $550^{\circ} \mathrm{C}$ \\
\hline$E(\mathrm{MPa})$ & 186100 & 182400 & 169700 & 156500 & 154000 \\
\hline$\epsilon_{\mathrm{f}}^{\prime}(\mathrm{mm} / \mathrm{mm})$ & 4.12 & 7.87 & 7.89 & 2.4 & 2.77 \\
\hline$c$ & -0.875 & -0.972 & -0.978 & -0.874 & -0.898 \\
\hline$\sigma_{\mathrm{f}}^{\prime}(\mathrm{MPa})$ & 2345 & 4745 & 3088 & 1721 & 1201 \\
\hline$b^{\prime}$ & -0.0937 & -0.1709 & -0.132 & -0.0874 & -0.0668 \\
\hline
\end{tabular}

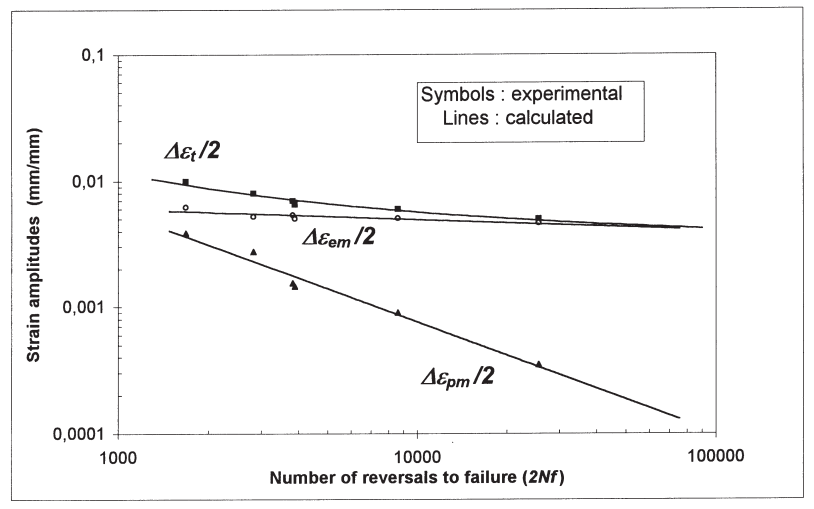

Fig. 4. Strain-life plot at $500^{\circ} \mathrm{C}$.

$\left(\sigma_{\mathrm{f}}^{\prime} / E\right) \cdot\left(2 N_{\mathrm{f}}\right)^{b^{\prime}}$ where $\Delta \epsilon_{\mathrm{em}}, \sigma_{\mathrm{f}}^{\prime}, E$ and $b^{\prime}$ are, respectively, the elastic strain amplitude at "half life", the strength coefficient, the Young's modulus and the strength exponent, total strain-life is well predicted. Coefficient values are listed in Table 3 for each temperature, and Fig. 4 shows an example of the strain-life plot at $500^{\circ} \mathrm{C}$.

\section{Isothermal cyclic behaviour modelling}

\subsection{Plastic strain evolution and cyclic stress-strain behaviour}

A more detailled analysis of the variation of the plastic strain with respect to the number of cycles shows in all cases a tendancy towards saturation. The ratio $\Delta \epsilon_{\mathrm{p}} / \Delta \epsilon_{\mathrm{pm}}$ (plastic strain/half life plastic strain) is plotted in Fig. 5 against $N /(N f / 2)$ (cycle number/half life cycle

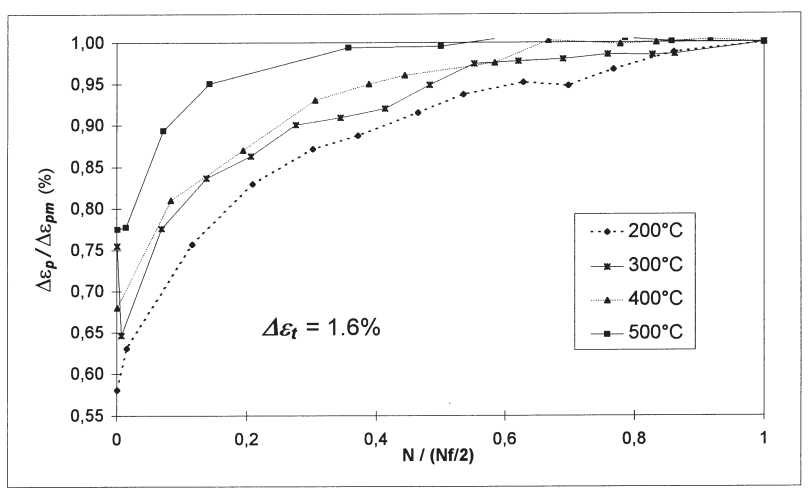

Fig. 5. Plastic strain evolution during cycling. number) for a total fatigue strain-amplitude of $1.6 \%$ and different temperatures. The following points can be noted: first, to reach saturation, relative plastic strain evolution is more important at low temperature (45\% for $\left.200^{\circ} \mathrm{C}\right)$ than at higher temperatures $\left(20 \%\right.$ for $\left.500^{\circ} \mathrm{C}\right)$; second, at higher temperatures $\left(500^{\circ} \mathrm{C}\right)$, close to the tempering temperature, the plastic strain reaches a quasisaturated value after only $30 \%$ of the half-life, compared to $70 \%$ for lower temperatures; third, the similarity of the shape of the curves at all temperatures, indicates an increase of the plastic-strain amplitude saturation rate with temperature.

Moreover, it is observed that the plastic-strain amplitude at half-life $\Delta \epsilon_{\mathrm{pm}}$ (which corresponds to the saturated strain amplitude in case of saturation) is linearly well correlated $\left(r^{2}=0.94\right)$ to the total strain amplitude whatever the test temperature (Fig. 6) providing the temperature is lower than tempering temperature $\left(<510^{\circ} \mathrm{C}\right)$. If we assume that the level of the saturated plastic strain is the consequence of a stabilized cyclic dislocation density, the tests have shown that this dislocation density depends only on the total cyclic strain amplitude (and not on temperature), and that the number of cycles to reach plastic strain saturation (and the associated dislocation density saturation) is temperature dependent.

The kinematic hardening portion of the succesive cyclic stress-strain curves $\left(\Delta \sigma / 2, \Delta \epsilon_{\mathrm{p}} / 2\right)$ have also been compared to the initial load increase $\left(\Delta \sigma, \Delta \epsilon_{\mathrm{p}}\right)$. It was found that the shape of these curves undergoes no evolution as illustrated for example in Fig. 7 for the test at $500^{\circ} \mathrm{C}$ and $\Delta \epsilon_{\mathrm{t}}=1.6 \%$.

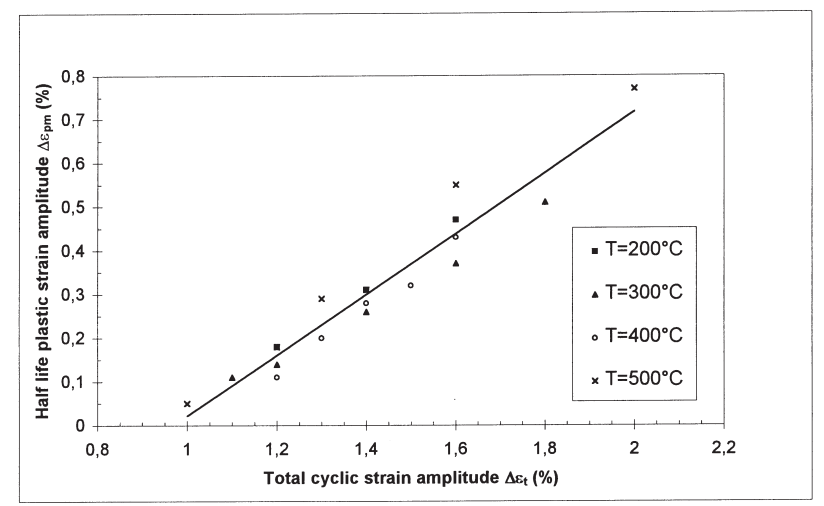

Fig. 6. Total and half-life strain correlation. 


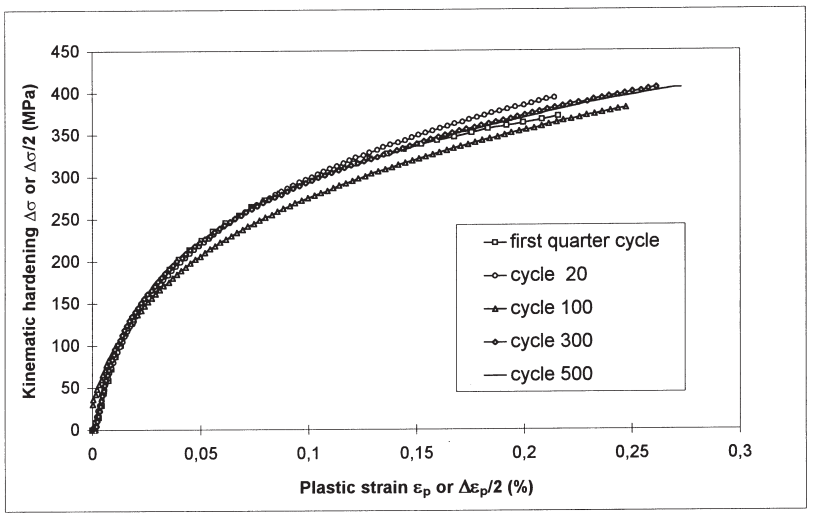

Fig. 7. Kinematic hardening curves over the cycles at $500^{\circ} \mathrm{C}$ and $\Delta \epsilon t$ $=1.6 \%$.

\subsection{Non-linear kinematic and isotropic hardening model}

According to the previous experimental behaviour, an elasto-plastic non-linear kinematic and isotropic hardening model is proposed to describe the cyclic stress-strain behaviour. This model is formulated in the framework of the thermodynamics of irreversible processes. A recall of this theory and a review of the different models developed up to now can be found in [14].

In particular, the isotropic variable $(R)$ is modified to allow a realistic representation of the material cyclic softening (Fig. 2), i.e. the two-stage softening consisting of a primary rapid load decrease, followed by secondary linear cyclic softening. Thus, similarly with expressions used in [14] for creep description, the dependence of the isotropic variable on the number of cycles is expressed as:

$R(p)=Q_{1} \cdot p+Q_{2}(q) \cdot(1-\exp (-b \cdot p))$

with:

$Q_{2}(q)=Q_{2 \infty} \cdot(1-\exp (-2 \mu \cdot q))$

where $p$ is the cumulative plastic strain, $q$ the half of the maximum cyclic plastic strain amplitude reached at the current number of cycles $\left(\Delta \epsilon_{\mathrm{pmax}} / 2\right), b, Q_{1}, Q_{2 \infty}, \mu$ are material and temperature dependent parameters.

$Q_{2}(q)$ accounts for the memory of the plastic strain paths, and allows us to take into account the fact that the materials softening behaviour is dependent on the initial strain amplitude. Moreover, such a variable allows cyclic stress-strain behaviour modelling, even if the total strain amplitude varies.

As a consequence, the constitutive equations for the isothermal non-linear elasto-plastic behaviour description is as follows (in the one-dimensional tension-compression form):

$$
\begin{aligned}
& \epsilon_{\mathrm{t}}=\epsilon_{\mathrm{e}}+\epsilon_{\mathrm{p}} \\
& |\sigma-X|-R-k=0 \\
& \mathrm{~d} X=C \cdot a \cdot \mathrm{d} \epsilon_{\mathrm{p}}-C \cdot X \cdot\left|\mathrm{d} \epsilon_{\mathrm{p}}\right| \\
& \mathrm{d} R=b \cdot\left(Q_{1} \cdot p+Q_{2}(q)-R\right) \cdot \mathrm{d} p+Q_{1} \cdot \mathrm{d} p
\end{aligned}
$$

where: $X$ and $R$ are, respectively, the non-linear kinematic and isotropic hardening variables, $k$ the initial true elastic limit (at $0.002 \%$ ), and $C, a$ are material and temperature dependent parameters. In our case, $C$ and $a$ are chosen independent of $p$ as the shape of the kinematic hardening curve is not cycle dependent (Fig. 7).

\subsection{Model coefficient indentification}

In tension-compression, analytical integration of Eq. (4) and Eq. (5) is possible, and identification of the model coefficients is made as explained below.

\subsubsection{Kinematic variable coefficient identification}

For the first quarter cycle-i.e. during the initial load increase, where $R=0$ - of the LCF test, the integration of Eq. (4), combined with Eq. (3) leads to:

$\sigma=X+k=a \cdot\left(1-\exp \left(-C \cdot \epsilon_{\mathrm{p}}\right)\right)+k$.

Knowing that a good representation of the experimental curve at high plastic strain levels (up to $0.5 \%$ ) is not possible with one kinematic hardening variable [14], the kinematic variable is expressed as a sum of two variables $X_{1}$ and $X_{2}$, the second variable takes over from the first after saturation of the exponential (around $\epsilon_{\mathrm{p}}=$ $0.2 \%)$. Thus:

$$
\begin{aligned}
\sigma & =X_{1}+X_{2}+k=a_{1} \cdot\left(1-\exp \left(-C_{1} \cdot \epsilon_{p}\right)\right) \\
& +a_{2} \cdot\left(1-\exp \left(-C_{2} \cdot \epsilon_{p}\right)\right)+k .
\end{aligned}
$$

Coefficients $a_{1}, a_{2}, C_{1}$ and $C_{2}$ are identified with a quadratic regression analysis (Matlab ${ }^{\mathrm{TM}}$ ) between the experimental curve and the analytical expression. Fig. 8 shows the quality of the regression for the different temperatures and Table 4 contains the values.

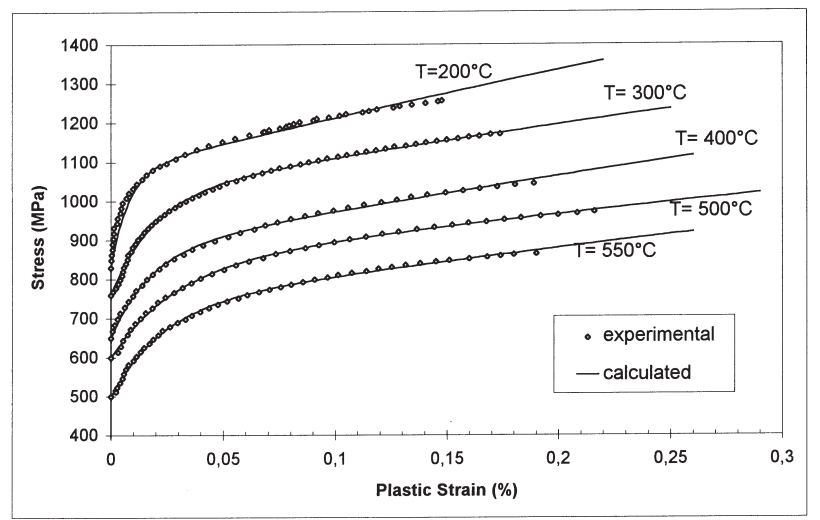

Fig. 8. Kinematic variable: experimental and identified curves. 
Model coefficients

\begin{tabular}{|c|c|c|c|c|c|}
\hline Temperature $\left({ }^{\circ} \mathrm{C}\right)$ & 200 & 300 & 400 & 500 & 550 \\
\hline$k(\mathrm{MPa})$ & 830 & 760 & 650 & 600 & 500 \\
\hline$a_{1}(\mathrm{MPa})$ & 247 & 243 & 221 & 229 & 229 \\
\hline$C_{1}$ & 12731 & 5553 & 5694 & 3563 & 4370 \\
\hline$a_{2}(\mathrm{MPa})$ & 1424 & 1085 & 1069 & 759 & 835 \\
\hline$C_{2}$ & 100 & 100 & 100 & 100 & 100 \\
\hline$Q_{1}(\mathrm{MPa})$ & -2.36 & -3.739 & -3.858 & -5.148 & -6.963 \\
\hline$Q_{2 \infty}(\mathrm{MPa})$ & -42025 & -20436 & -22263 & -23347 & -26817 \\
\hline$b$ & 1.294 & 2.096 & 3.484 & 4.432 & 4.897 \\
\hline
\end{tabular}

\subsubsection{Isotropic variable coefficient identification}

Evolution of the semi-stress amplitude $(\Delta \sigma / 2)$ curves for the different levels of initial total strain amplitude are used to determine the isotropic variable coefficients.

Analytical integration of Eq. (5) gives:

$R(p)=Q_{1} \cdot p+Q_{2}(q) \cdot(1-\exp (-b \cdot p))$

i.e., Eq. (1). Making the usual assumption that the cumulative plastic strain is expressed by $p=2 \cdot N \cdot \Delta \epsilon_{\mathrm{pm}}(N=$ current cycle number), and considering for simplification purposes that $2 \mu \cdot q$ is very small so that $(1-\exp (-$ $2 \mu \cdot q)) \approx 2 \mu \cdot q$ and $\Delta \epsilon_{\mathrm{pmax}}=\Delta \epsilon_{\mathrm{pm}}$, Eq. (1) becomes (if we choose without loss of generality $\mu=1$ ):

$$
\begin{aligned}
R(p) & =2 \cdot Q_{1} \cdot N \cdot \Delta \epsilon_{\mathrm{pm}} \\
& +Q_{2 \infty} \cdot \Delta \epsilon_{\mathrm{pm}}\left(1-\exp \left(-2 \cdot b \cdot N \cdot \Delta \epsilon_{\mathrm{pm}}\right)\right) .
\end{aligned}
$$

Fig. 9 shows the signification of the different coefficients on a schematic cyclic strain softening curve:

- $2 \cdot Q_{1} \cdot \Delta \epsilon_{\mathrm{pm}}$ is the slope of the semi-stress softening, in the portion of the curve where the exponential term is close to 0 , i.e. for a high number of cycles,

- $Q_{2 \infty} \cdot \Delta \epsilon_{\mathrm{pm}}$ is the difference between the stress at first cycle reversal and the intersection of the linear portion and the stress axis,

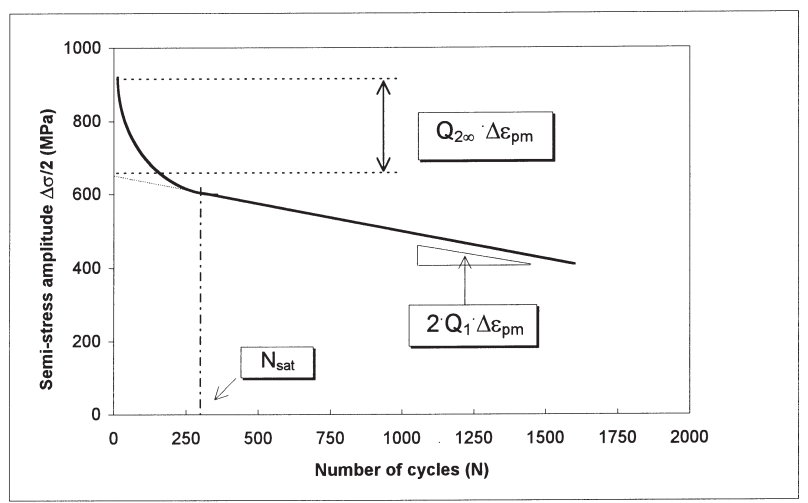

Fig. 9. Schematical representation of the cyclic strain softening curve.
- $b$ is calculated for the cycle number where the exponential term is saturated (i.e. $\approx 0.001$ ); if this cycle number is $N_{\mathrm{sat}}$, then $-2 \cdot b \cdot N_{\mathrm{sat}} \cdot \Delta \epsilon_{\mathrm{pm}}=$ $\operatorname{Ln}\left(0.001 / Q_{2 \infty}\right)$.

For each temperature, linear regression analysis allows the determination of the values listed in Table 4 .

An example of the comparison between the calculated isotropic softening curves and experimental ones for various strain amplitudes and temperatures is shown in Fig. 10. It can be seen that the initial calculated deconsolidation is often faster than the experimental one. This can be explained by the fact that for the calculated variable evolution, we have considered (as usual for simplification) that $\Delta \epsilon_{\mathrm{pmax}}=\Delta \epsilon_{\mathrm{pm}}$ and $p=2 \cdot N \cdot \Delta \epsilon_{\mathrm{pm}}$ from the first cycle. A better representation may be obtained in introducing the actual plastic strain evolution over the number of cycles derived from the experimental evolution of Fig. 5.

\subsection{Validation of model accuracy}

Model validation is done by comparing the experimental and the calculated evolution of the stress-strain loops over the number of cycles.

A computer programme was written to enable the simulation of a low cycle fatigue test to be performed between two total strain amplitudes. During each rever-

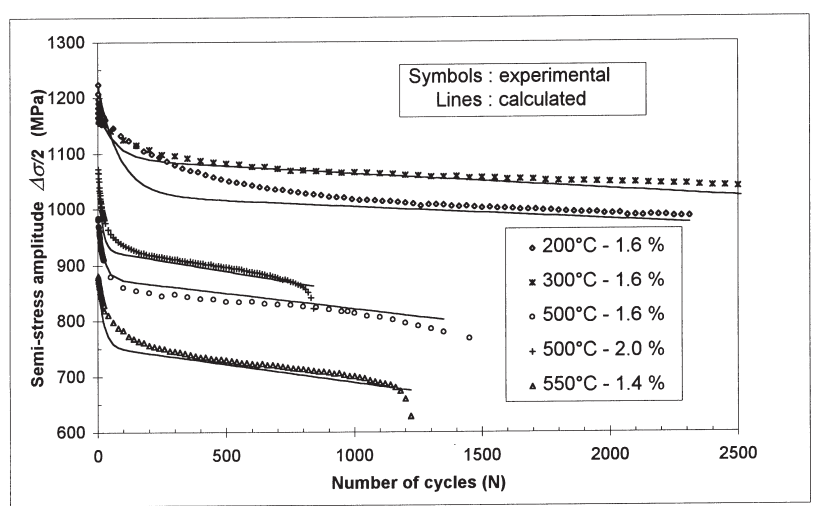

Fig. 10. Isotropic variable $R$ : experimental and identified curves. 
sal of the $N$ th cycle of the tension-compression test, the analytical integration of Eq. (4) and Eq. (5) combined with Eq. (3) allows simple expression of $\sigma$ with $\epsilon_{\mathrm{p}}$ and material coefficients listed in Table 4:

$$
\left.\sigma\left(\epsilon_{\mathrm{p}}, N\right)\right)=X_{1}\left(\epsilon_{\mathrm{p}}, \nu\right)+X_{2}\left(\epsilon_{\mathrm{p}}, \nu\right)+\nu R(p)+\nu k
$$

with

$$
\begin{aligned}
& X_{\mathrm{i}}\left(\epsilon_{\mathrm{p}}, \nu\right)=\nu \cdot a_{\mathrm{i}}+\left(X_{0 \mathrm{i}}-\nu \cdot a_{\mathrm{i}}\right) \cdot\left(1-\exp \left(-\nu \cdot C_{\mathrm{i}}\right.\right. \\
& \left.\left(\epsilon_{\mathrm{p}}-\epsilon_{\mathrm{p} 0}\right)\right) \\
& \quad i=1 \text { and } 2
\end{aligned}
$$

where $\nu=+1$ or -1 , respectively, if the reversal is deformation increasing or decreasing, $X_{0 \mathrm{i}}$ and $\epsilon_{\mathrm{p} 0}$ are the values of $X_{\mathrm{i}}$ and $\epsilon_{\mathrm{p}}$ at the last plastic strain reversal, and $R(p)$ is given by Eq. (7).

$\epsilon_{\mathrm{p}}$ is increased step by step up to the point where the upper or lower total strain used during testing was reached; at this point a new reversal is calculated. Calculated $\left(\sigma, \epsilon_{\mathrm{p}}\right)$ curves can be compared with experimental ones.

A typical comparison between the experimental and calculated cycles for a fully reversed LCF test is presented in Fig. 11(a) and (b) for the test performed at $500^{\circ} \mathrm{C}$ with a total strain amplitude $\Delta \epsilon_{\mathrm{t}}=1.6 \%\left(\Delta \epsilon_{\mathrm{tmax}}\right.$ $=+0.8 \%, \Delta \epsilon_{\mathrm{tmin}}=-0.8 \%$ ) for loops $1,10,20,50$, $100,200,500,1000$.
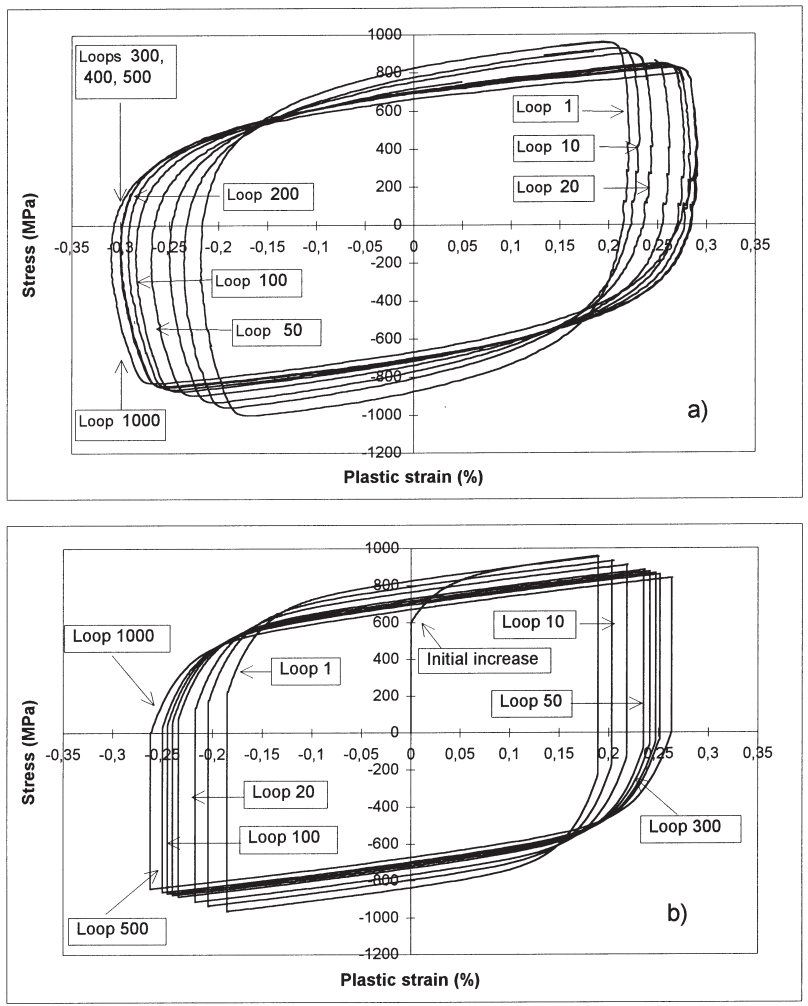

Fig. 11. Cyclic behaviour: $500^{\circ} \mathrm{C}$, total strain amplitude $\Delta \epsilon_{\mathrm{t}}=1.6 \%$; (a) experimental loops; (b) model simulation loops.
The shape and evolution of the loops is similar between the model results and the experimental ones. The Baushinger effect is simulated as well as the increase of plastic strain amplitude and the decrease of stress at reversals. This validates the model with respect to the domain in which the identification was done (it should nevertheless be remembered here that no experimental loop was used for model identification).

\subsection{Predictive capacity verification}

To verify the predictive capacity of the model two non-symmetrical LCF tests were simulated and experimentally conducted. The first one was carried out at $500^{\circ} \mathrm{C}$ between a maximum total strain amplitude of $\Delta \epsilon_{\mathrm{tmax}}=+1 \%$ and a minimum of $\Delta \epsilon_{\mathrm{tmin}}=-0.5 \%$; the second at $400^{\circ} \mathrm{C}$ between the total strain range $\Delta \epsilon_{\text {tmin }}$ $=-1 \%$ and $\Delta \epsilon_{\mathrm{tmax}}=+0.3 \%$.

Predicted material response for the first test $\left(500^{\circ} \mathrm{C}\right)$ is presented in Fig. 12(a) and (b) for total strain and plastic strain evolution. It can be seen that during the first few cycles the model predicts a relaxation of the mean stress, and at the same time a plastic strain range which is located in the positive strain domain.

Experimental cyclic stress-strain responses are shown
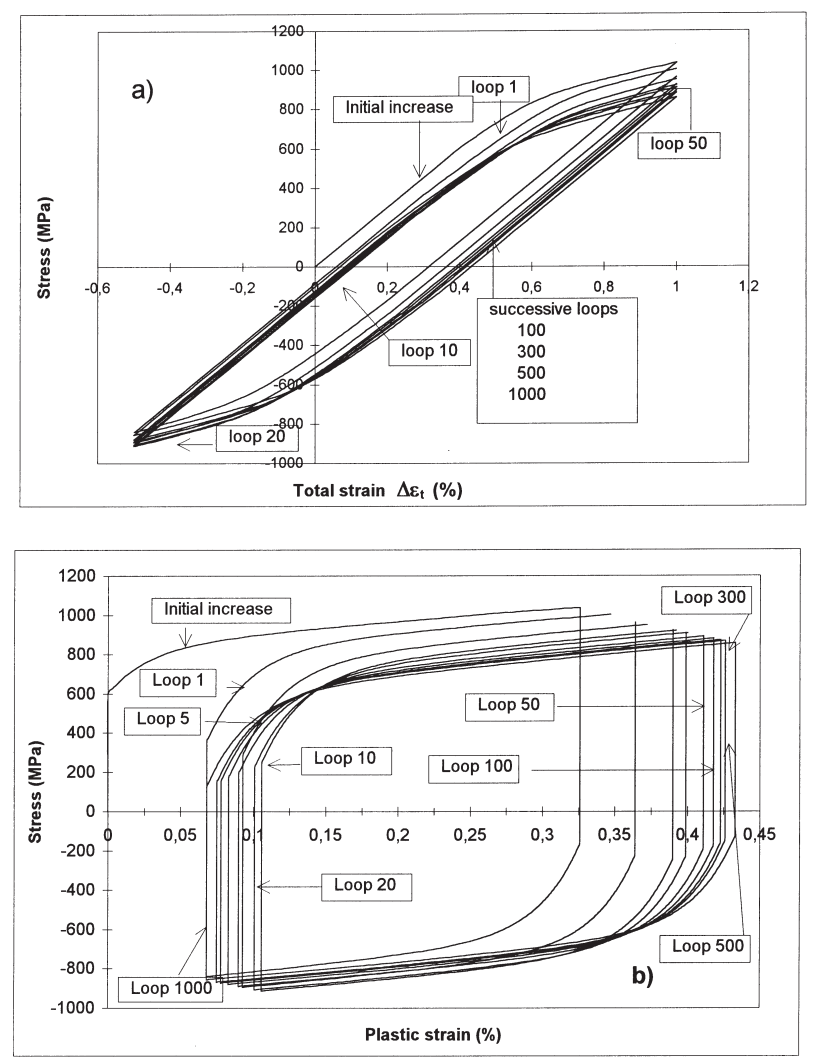

Fig. 12. Calculated non-symmetrical cyclic behaviour: $500^{\circ} \mathrm{C}$, total strain amplitude $\Delta \epsilon_{\operatorname{tmin}}=-0.5 \%, \Delta \epsilon_{\operatorname{tmax}}=+1.0 \%$; (a) total strain plot; (b) plastic strain plot. 

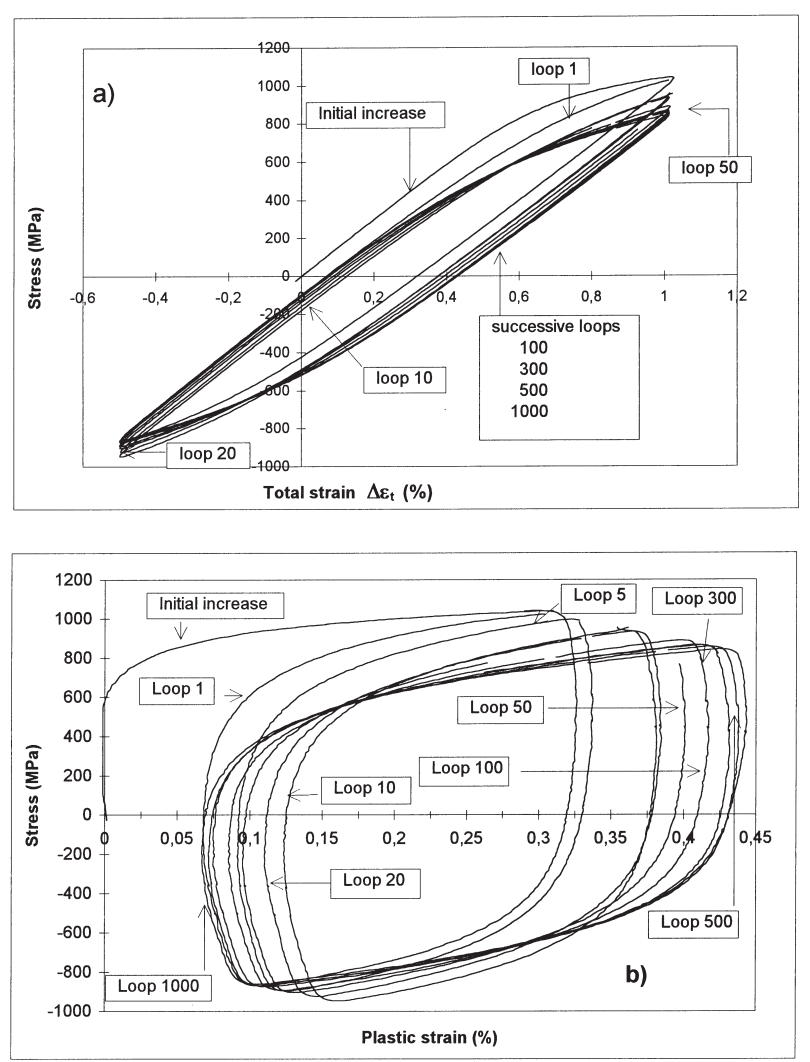

Fig. 13. Experimental non-symmetrical cyclic behaviour: $500^{\circ} \mathrm{C}$, total strain amplitude $\Delta \epsilon_{\operatorname{tmin}}=-0.5 \%, \Delta \epsilon_{\operatorname{tmax}}=+1.0 \%$; (a) total strain plot; (b) plastic strain plot.

in Fig. 13(a) and (b) for total and plastic strain evolution. The good correlation between the predicted and the experimental results (also verified for the test at $400^{\circ} \mathrm{C}$ ) shows evidence that such models based on the thermodynamics of irreversible processes are well suited for the description of cyclic fatigue behaviour of martensitic tool steels.

\section{Conclusions}

The Low Cycle Fatigue behaviour of a martensitic tool steel was investigated in the temperature range $200^{\circ} \mathrm{C}$ to $550^{\circ} \mathrm{C}$ and total strain range $1 \%$ to $2 \%$. The following conclusions can be drawn:

1. Whatever the test temperature and strain range, the steel shows cyclic softening without stabilization; the higher the initial strain amplitude, the more the material softens. The level of the plastic strain amplitude at halflife was found to be only dependent on the initial total strain, but the evolution rate is temperature dependent.

2. The Manson-Coffin and Basquin analysis is relevant to life-time prediction when using the plastic and elastic strain amplitudes at half-life. Rupture mainly initiates on inclusions (for low temperatures) or oxide cracks (at higher temperatures) and always propagates transgranularly.

3. An elasto-plastic non-linear kinematic and isotropic hardening model, formulated in the frame of the thermodynamics of irreversible processes, was identified to describe the cyclic stress-strain behaviour. The following major experimental results taken into account for the formulation are:

- the kinematic variable $(X)$ is independant of the number of cycles for a given temperature,

- the isotropic variable $(R)$ is depicted as a summation of an exponential part and a linear decreasing part,

- a strain path history variable is introduced to describe the dependance between the softening level and the initial total strain amplitude.

4. The model is able to reproduce the experimental behaviour even in test condition not used for model identification, like non-symmetrical total strain LCF tests (Baushinger effect and mean stress relaxation are well modelled).

\section{Acknowledgements}

The authors gratefully acknowledge the French Research Action on Forging for their support in supplying the test specimens, as well as Serge Tovar for technical assistance on microstructural observations.

\section{References}

[1] Nagao Y, Knoer M, Altan T. J of Mat. Processing Technology 1994;46:73.

[2] Lange K, Hettig A, Knoerr M. J of Mat. Processing Technology 1992;35:495.

[3] Iwama T, Morimoto Y. 28th ICFG plenary meeting, Copenhagen, 1992.

[4] Brucelle O, Bernhart G. J of Mat. Processing Technology 1998; in press.

[5] Benallal A, Ben Cheikh A. 2nd Int. Conf. on Constitutive Laws for Engineering Materials,1987, Desai et al., 667

[6] Chaboche JL, Lemaitre J, Marquis D, Savalle S. Eur J Mechanics 1991;10:424.

[7] Marquis D. Doctoral thesis, University Paris 6, 1979.

[8] Shi HJ, Pluvinage G. Fatigue 1994;16:549.

[9] Burlet H. Doctoral thesis, ENSMP, 1987.

[10] Necib K, Revel P. Materials Science and Engineering 1997;A237:126.

[11] Delagnes D. Doctoral thesis, ENSMP, 1998.

[12] Chai H, Fan Q. Proceedings of the 5th International Conference on Fatigue and Fatigue Thresholds, 1993:195.

[13] Skelton RP, Loveday MS. Materials at High Temperatures 1997;14:53.

[14] Lemaitre J, Chaboche JL. Mechnics of solid materials. Cambridge: Cambridge University Press, 1990. 